\title{
Coordinated Control Scheme for Ancillary Services from Offshore Wind Power Plants to $A C$ and DC Grids
}

Sakamuri, Jayachandra N.; Altin, Müfit; Hansen, Anca Daniela; Cutululis, Nicolaos Antonio; Rather, Zakir Hussain

\section{Published in:}

Proceedings of 2016 IEEE PES General Meeting

Link to article, DOI:

10.1109/PESGM.2016.7741636

Publication date:

2016

Document Version

Peer reviewed version

Link back to DTU Orbit

Citation $(A P A)$ :

Sakamuri, J. N., Altin, M., Hansen, A. D., Cutululis, N. A., \& Rather, Z. H. (2016). Coordinated Control Scheme for Ancillary Services from Offshore Wind Power Plants to AC and DC Grids. In Proceedings of 2016 IEEE PES General Meeting IEEE. https://doi.org/10.1109/PESGM.2016.7741636

\section{General rights}

Copyright and moral rights for the publications made accessible in the public portal are retained by the authors and/or other copyright owners and it is a condition of accessing publications that users recognise and abide by the legal requirements associated with these rights.

- Users may download and print one copy of any publication from the public portal for the purpose of private study or research.

- You may not further distribute the material or use it for any profit-making activity or commercial gain

- You may freely distribute the URL identifying the publication in the public portal 


\section{Coordinated Control Scheme for Ancillary Services from Offshore Wind Power Plants to AC and DC Grids}

\author{
Jayachandra N. Sakamuri, Mufit Altin, \\ Anca D. Hansen, Nicolaos A. Cutululis \\ Department of Wind Energy \\ Technical University of Denmark \\ Ris $\varnothing$, Roskilde, Denmark \\ jays@dtu.dk
}

\author{
Zakir Hussain Rather \\ Department of Electronics and Electrical Engineering \\ Indian Institute of Technology Guwahati \\ Guwahati, India \\ zakir.rather@iitg.ac.in
}

\begin{abstract}
This paper proposes a new approach of providing ancillary services to AC and DC grids from offshore wind power plants (OWPPs), connected through multi-terminal HVDC network. A coordinated control scheme where OWPP's AC grid frequency modulated according to DC grid voltage variations is used to detect and provide the ancillary service requirements of both $\mathrm{AC}$ and DC grids, is proposed in this paper. In particular, control strategies for onshore frequency control, fault ridethrough support in the onshore grid, and DC grid voltage control are considered. The proposed control scheme involves only local measurements and therefore avoids the need of communication infrastructure otherwise required for communication based control, and thus increases the reliability of the control system. The effectiveness of the proposed control scheme is demonstrated on a MTDC connected wind power system developed in DIgSILIENT PowerFactory.
\end{abstract}

Index Terms - ancillary services, fault ride through, frequency control, HVDC grid voltage control, integration of wind power.

\section{INTRODUCTION}

During recent years, there has been a significant penetration of offshore wind power plants (OWPPs) into power systems and this trend is expected to continue in the future [1]. Traditionally, active power from OWPPs is transmitted to the mainland grid through submarine high voltage AC (HVAC) cables [2]. However, increased active power from OWPPs combined with long distances to the shore has encouraged the use of the voltage source converter based high voltage direct current (VSC- HVDC) transmission system as a feasible and economical solution for bulk power transmission from OWPPs to the onshore grid [3]. Accordingly, increased penetration of wind power into power systems over past decades has introduced various technical challenges, such as onshore gird frequency control and fault ride through for $\mathrm{AC}$ grid faults, for secure and stable operation of the system. In order to counter such challenges, transmission system operators (TSOs)/system regulators have introduced new grid codes that are upgraded on regular basis [4],[5]. Among these grid codes, frequency support and Fault Ride-Through (FRT) capability are important for AC grids as

The researches leading to these results have received funding from the People Program (Marie Curie Actions) of the European Union's Seventh Framework Program FP7/2007-2013/ under REA grant agreement no. 317221, project title MEDOW. these require the fast control of active power output from HVDC connected offshore WPPs. Further, the active participation of offshore WPPs in DC grid voltage control is important especially when the share of wind power feeding the DC grid is significant [6]. The reason is the dynamic challenges imposed by DC grid voltage control are major; therefore, very fast active power control action is needed to ensure stable DC grid operation.

Since the HVDC system decouples the OWPPs from the mainland AC grid, OWPPs are unable to detect and respond to onshore grid disturbances based on their local measurements near the WTs. In the literature [7]-[9], two methods for frequency control to replicate the onshore frequency to offshore grid are typically described; (1) Communication based control (2) Coordinated control. The first method is based on the transmission of onshore frequency to the offshore converter station through appropriate communication channels, while the second method aims at emulating the onshore frequency variations onto the offshore grid through appropriate control blocks. Communication based control requires sophisticated communication network between each WPP converter station to the onshore AC grid. The coordinated frequency control is based on a cascaded reproduction of onshore frequency at offshore AC grid through supplementary droop control loops at onshore and offshore converter stations by regulating the DC voltage in the HVDC grid. For a two terminal HVDC system, communication based method might be sufficient while for a multi-terminal DC (MTDC) system coordinated control approach is necessary due to reliability issues with the communication links between each WPP and associated AC grids [8].

The main concern for the FRT support from OWPPs connected through HVDC system is the delay in detection and communication of onshore fault at the offshore station, which results in an unacceptable rise of DC voltage leading to trip of the HVDC link, thus blocking the power flow from OWPPs [10]. One of the possible solutions to avoid such type of issue is to use expensive DC chopper in the onshore HVDC station to dissipate the excess energy in the DC link [6]. To avoid the 
requirements of DC chopper/reduce its size, a method of fast reduction of active power from the OWPPs in MTDC grid based on modulating the $\mathrm{AC}$ voltage or frequency in the offshore AC Grid has been described in [11]. However, as in this method, there is intentional voltage reduction in the offshore AC grid; the voltage dead band for dynamic reactive power controllers of the OWPPs should be adjusted to avoid offshore AC voltage support within the preset dead band during the event. However, this approach will have detrimental impact during a voltage event in the offshore grid as such type of approach will be in contradiction to the requirement of additional reactive current injection during a fault in the offshore AC grid. Therefore, frequency modulation approach, where instead of AC voltage modulation, the offshore AC grid frequency is increased while DC link voltage exceeds the threshold value, is considered in this paper.

For higher share of wind power in MTDC systems, it is imperative that such WPPs feeding into the DC grid shall also provide DC grid voltage support. However, to avail such type of voltage support service from WPPs, high speed measurement and communication infrastructure will be required [12]. Moreover, in the literature [6]-[12], different ancillary services from OWPPs (i.e. frequency support, FRT support from OWPPs) to AC grid have been studied individually and independently. However, this independent study approach may not be sufficient as the controllers designed for one type of service may not be effective for other type of service. For example, to provide onshore FRT support from OWPPs, the offshore AC voltage is intentionally reduced by blocking dynamic reactive current controllers from OWPPs which is not recommended for faults within the offshore AC grid itself as described earlier. Also, during disturbances in the DC gird, the response of WPPs should be fast enough to mitigate the DC grid voltage variations as the dynamics of DC grid is faster than AC grid. The controllers designed for onshore AC grid frequency control may therefore not be fast enough for DC grid voltage control. Hence, a coordinated control scheme for ancillary services for $\mathrm{AC}$ (frequency control, FRT support) and DC grids (DC voltage control) from MTDC connected OWPPs based on offshore frequency modulation approach is proposed in this paper. The limitation of this approach for each ancillary service is also discussed. Time domain simulations are carried out in the dedicated power system tool, PowerFactory platform, to verify the effectiveness of the proposed control scheme. The rest of the paper is organised as follows. Section II describes the modeling of the Multi-Terminal HVDC system and OWPPs. The proposed methodology for ancillary services from WPPs is discussed in section III. The simulation results for different ancillary services are presented in section IV, followed by concluding remarks provided in section $\mathrm{V}$.

\section{MODEL DESCRIPTION}

The grid layout considered in this paper consists of 2 onshore AC grids and one offshore grid with OWPPs connected all together through a 3-terminal HVDC as shown in Fig. 1. A brief description of the simulation models for the onshore AC grid, WPP and the HVDC interconnection is given below.

\section{A. Onshore AC Grid Model:}

The onshore AC Grid is modelled as a lumped synchronous machine with rated power of 1200 MVA. Standard models and parameters for the Governor, Automatic Voltage Regulator and Power System Stabilizer have been developed [13]. Relevant parameters based on machine MVA base used in this research study are summarised in Table 1.

TABLE I : SYNCHRONOUS MACHINE PARAMETERS

\begin{tabular}{|l|c|c|}
\hline \multicolumn{1}{|c|}{ Parameter } & Value & Unit \\
\hline System regulating energy, $\mathrm{K}_{\mathrm{sys}}$ & 10 & $\mathrm{pu}$ \\
Governor time constant, $\mathrm{T}_{\mathrm{P}}$ & 0.1 & $\mathrm{~s}$ \\
Turbine time constant , $\mathrm{T}_{1}$ & 1.0 & $\mathrm{~s}$ \\
Inertia constant ,H & 8.5 & $\mathrm{~s}$ \\
\hline
\end{tabular}

\section{B. HVDC System Model:}

A 3-terminal HVDC interconnection based on three VSCs, modelled as ideal voltage sources behind reactance is shown in Fig. 1. It is based on symmetrical monopole configuration having same voltage with opposite polarity at the converter terminals. The given MTDC system is operated based on power-voltage $\left(P-V_{d c}\right)$ droop control method due to its superiority in power sharing and reliability of MTDC system as explained in [14]. PowerFactory's built-in converter, pimodel of the cable, and standard transformer models [15] have been used in this study. A brief description of the grid layout is summarised in Table II.

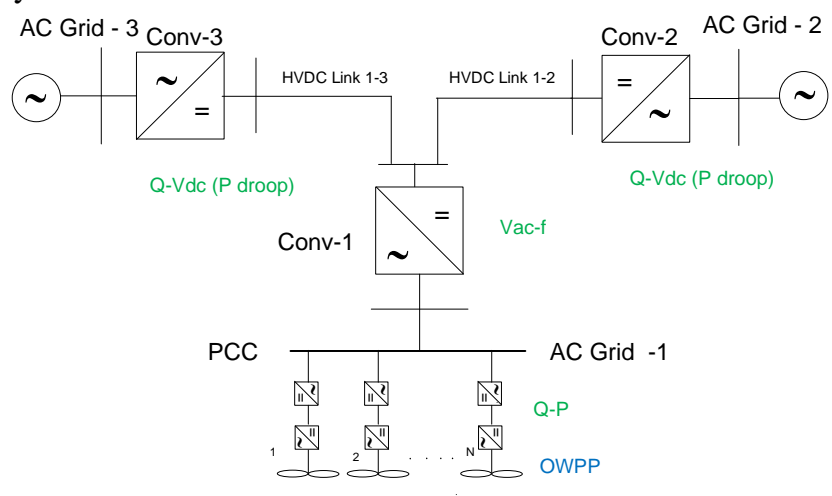

Fig. 1 Grid layout of the 3 terminal HVDC system

TABLE II : DESCRIPTION OF THE GRID LAYOUT IN FIG. 1

\begin{tabular}{|l|c|c|}
\hline \multicolumn{1}{|c|}{ Parameter } & Value & Unit \\
\hline Onshore AC Voltage & 380 & $\mathrm{kV}$ \\
Offshore AC Voltage & 155 & $\mathrm{kV}$ \\
DC Grid Voltage & 320 & $\mathrm{kV}$ \\
Converter MVA & 1060 & $\mathrm{MVA}$ \\
WPP Active Power Output & 1000 & $\mathrm{~kW}$ \\
\hline
\end{tabular}

1) Onshore HVDC Converters

The Conv-2 and Conv-3 in Fig 1 are the onshore HVDC converter stations connected to AC Grid-2 and AC Grid-3 respectively. They are responsible for maintaining the power balance in the DC system by keeping the DC voltage within the acceptable limits. The control block diagram for onshore HVDC converter is shown in Fig. 2. 


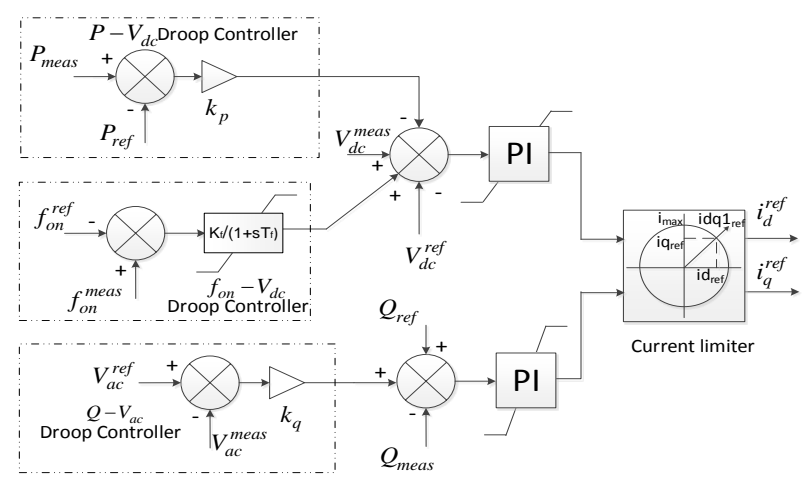

Fig. 2. Onshore HVDC converter control

The onshore HVDC converter control consists of two main controllers: one for active power balance control (DC voltage -active power droop) and other for reactive power control. The sharing of active power imbalance between the onshore converters depends on the active power droop constant $\left(k_{p}\right)$ of the $P-V_{d c}$ droop controller. The converter also controls the reactive power at converter bus through $\mathrm{AC}$ voltage droop $\left(Q-V_{a c}\right)$ so as to maintain the AC voltage within specified range. The current references provided by the outer controllers are then handled by an inner current controller operating in $d-q$ reference frame. A supplementary frequency-DC voltage droop $\left(f_{o n}-V_{d c}\right)$ controller in the outer loop $\mathrm{d}$-axis is responsible for modulating the DC voltage reference $\left(V_{d c}^{r e f}\right)$ proportional to the onshore frequency deviation. This controller not only allows exchange of frequency support between the two onshore AC systems but also allows OWPPs to participate in frequency control. This loop contributes to the power system frequency regulation in coordination with a DC voltage- frequency droop controller $\left(V_{d c}-f_{\text {off }}\right)$ at offshore HVDC converter, as depicted in Fig. 3, and active power controller of OWPP.

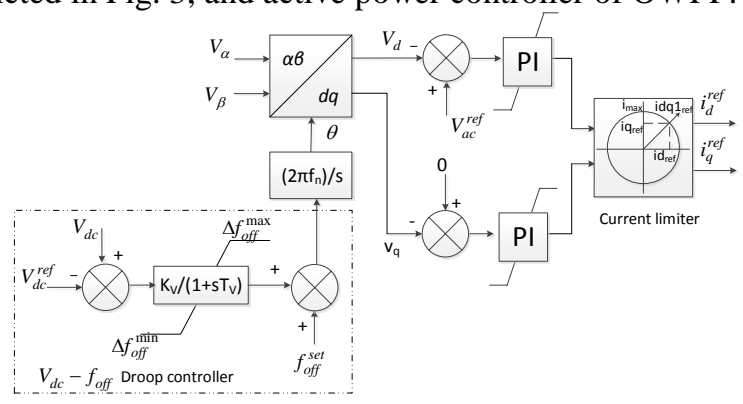

Fig. 3. Offshore HVDC converter control

\section{2) Offshore HVDC Converter}

The Conv-1 in Fig. 1 is the offshore HVDC converter station connecting the OWPP to the MTDC system. It is responsible for controlling the $\mathrm{AC}$ voltage magnitude and frequency of the offshore $\mathrm{AC}$ network at point of common connection (PCC) of the WPP and allows transferring the wind power output to the MTDC system. This is achieved through the use of a standard current controller whose references are provided by the outer controller illustrated in
Fig 3. A DC voltage-frequency droop controller $\left(V_{d c}-f_{\text {off }}\right)$ at the outer control loop changes the offshore AC grid frequency reference proportionally to the DC voltage deviation. This controller in coordination with active power controller of OWPP provides the active power support required for the ancillary services to AC and DC grids.

\section{Offshore Wind Power Plant Model:}

The OWPP is an aggregated IEC Type 4 wind turbine (WT) model based on the aggregation method for WTs given in [16]. The Type 4 WT model used in this study is based on generic approach proposed by the IEC Committee in Part 1 of IEC 61400-27 [17] for the short term power system stability studies. Additionally, this model is extended to include the dynamic features relevant for the study of ancillary services (such as onshore frequency control and FRT for AC grid and DC voltage control for DC grid) from WPPs [18].

\section{PRoposed COORdinATED CONTROL SCHEME}

In this paper, a coordinated offshore AC grid frequency modulation according to the DC grid voltage variation is proposed in order to represent the ancillary services requirements of $\mathrm{AC}$ and $\mathrm{DC}$ grids at offshore $\mathrm{AC}$ grid without depending on the dedicated communication links. The idea of this method is that the offshore HVDC converter modifies the offshore AC grid frequency proportional to the DC voltage variation measured at its terminals. The relation between offshore AC grid frequency and DC voltage is given in (1),(2), where $f_{\text {off }}^{\text {set }}$ is the offshore frequency during normal conditions and $f_{\text {off }}^{\text {ref }}$ is the reference offshore frequency according to $\mathrm{DC}$ grid voltage variation.

$$
\begin{aligned}
& f_{\text {off }}^{r e f}=f_{\text {off }}^{\text {set }}+\Delta f_{\text {off }} \\
& \Delta f_{\text {off }}=k_{v} \Delta V_{d c}
\end{aligned}
$$

The above relation in (1) and (2) is valid for the onshore FRT support and DC grid voltage support as the DC voltage variation is the result of the natural phenomenon caused by the respective ancillary service. For the WPP to provide the AC grid frequency control service, it requires an additional control mechanism ( $f_{o n}-V_{d c}$ droop as shown in Fig. 2) that translates the onshore AC grid frequency variations into DC voltage variations of MTDC system as given in (3). However, the $f_{o n}-V_{d c}$ droop control is activated only when the variation in the onshore frequency is above a certain dead band to avoid conflict with the $P-V_{d c}$ droop control of the onshore converter [9].

$$
\Delta V_{d c}=k_{f}\left(f_{o n}^{\text {meas }}-f_{o n}^{r e f}\right)
$$

Where $f_{o n}^{r e f}$ and $f_{o n}^{\text {meas }}$ is the reference and actual frequencies of the onshore $\mathrm{AC}$ grid respectively. The frequency variation in the offshore AC grid modifies the WT active power reference as given in (4)

$$
\begin{aligned}
& P_{W T}^{r e f}=P_{o p t}-\Delta P_{1}-\Delta P_{2} \\
& \Delta P_{1}=k_{d}\left(f_{\text {off }}-f_{\text {off }}^{\text {set }}\right), \Delta P_{2}=k_{\text {in }}\left(\Delta f_{\text {off }} / \Delta T\right)
\end{aligned}
$$


$P_{o p t}$ is the optimal power output of WT as determined by its maximum power point tracking control. $\Delta P_{1}$ is the power reference proportional to the frequency deviation from steady state value, whereas $\Delta P_{2}$ is proportional to the rate of change of frequency. The WT, hence the WPP active power output is regulated as defined in (4) in coordination with DC and AC grids to provide the required ancillary service.

\section{SimUlation AND DisCUSSION ON RESUlTS}

In this section, the effectiveness of the proposed coordinated control scheme to provide different ancillary services (frequency and FRT support for AC grid and DC voltage control for DC grid) from OWPP connected to MTDC system is discussed. The onshore AC grid frequency support is discussed in section A, while onshore FRT support and DC grid voltage support are discussed in section B and C respectively.

\section{A. Onhore AC Grid Frequency Support}

The power output from WPP (1000 MW) is shared between Grid-2 (500 MW) and Grid-3 (470 MW). A $10 \%$ load increase at $\mathrm{t}=10 \mathrm{~s}$ initiates an under frequency event in the AC Grid-2 of the test system shown in Fig.1. The effect of coordinated control on the frequency of AC Grid-2 and the corresponding offshore AC grid frequency is shown in Fig. 4 for different situations: A. Without coordinated control from WPP and Grid-3 B. With coordinated control from Grid-3 only, and C. With coordinated control from WPP and Grid3.The corresponding DC voltage and the active power output of the three converters are given in Fig. 5.

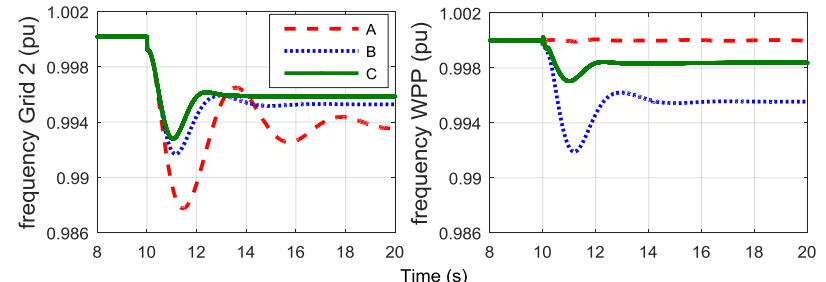

Fig. 4 Frequency of Grid-2 and offshore Grid. A -Without coordinated control B- Coordinated control from Grid-3 alone C- With coordinated control from Grid-3 and WPP

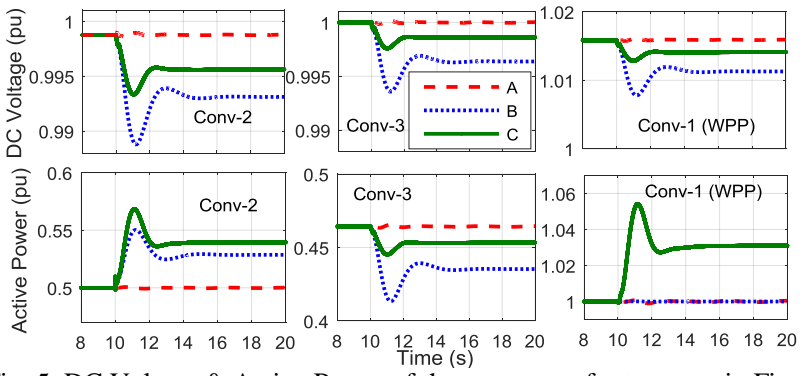

Fig. 5. DC Voltage \& Active Power of the converters for test case in Fig. 4

Due to coordinated frequency control action, the Conv-2 changes its DC voltage reference once it detects the frequency event; hence the overall DC Grid voltage profile is changed as shown in Fig. 5. This leads to the reduction of offshore AC grid frequency, as shown in Fig. 4, which initiates additional power output from WPP. Similarly, the power taken by Conv-3 is also reduced due to $P-V_{d c}$ droop control action, helping the fast recovery of AC Grid-2 frequency. It can be observed from Fig. 4 that with the coordinated frequency control, the frequency of the AC Grid -2 is improved with the active power contribution from AC Grid-3 (dotted line) alone compared to without coordinated control (dashed line). With the coordinated control from WPP along with AC Grid-3, the frequency of AC grid-2 is significantly improved (solid line). Moreover, the WPP participation in frequency control relives the burden on the AC Grid-3 by sharing the active power contribution.

\section{B. FRT support from OWPPs for Onshore Faults}

A 3- phase to ground fault is applied (at $\mathrm{t}=10 \mathrm{~s}$ for $200 \mathrm{~ms}$ ) at the converter AC side of AC Grid-3. The AC voltage of the AC Grid-3, DC voltage, and active power output of the three converters are shown in Fig. 6. During the fault, active power output of Conv-3 becomes zero. In contrast, the Conv-2 in AC Grid-2 is able to increase the power transmission in about $0.2 \mathrm{pu}$. This behavior is due to the previously mentioned $P-V_{d c}$ droop control action which regulates the active power extraction as a function of DC voltage variation. Moreover, it can be observed that the active power dynamics of the Conv2 is slower than the corresponding time constant observed in the active power reduction by Conv-3. This leads to additional energy stored in the DC grid, resulting in DC voltage rise. With the coordinated control; there is a rise in the offshore WPP AC grid frequency during the fault, as shown in Fig. 7, which reduces the WPP output power significantly. This results in reduced overvoltage in the DC grid and also relieves the stress on the Conv-2 by sharing active power contribution.

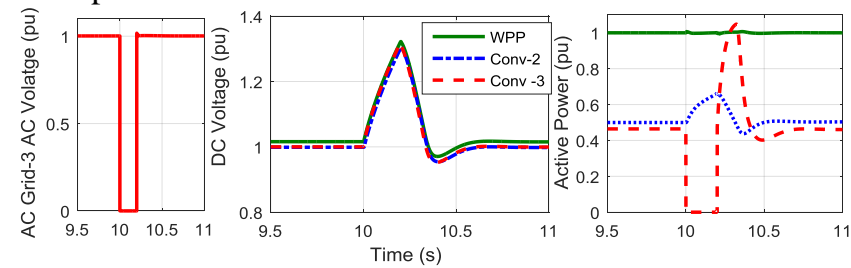

Fig. 6. AC Grid-3 AC Voltage, DC Voltage, Active Power of DC Grid without coordinated control from WPP
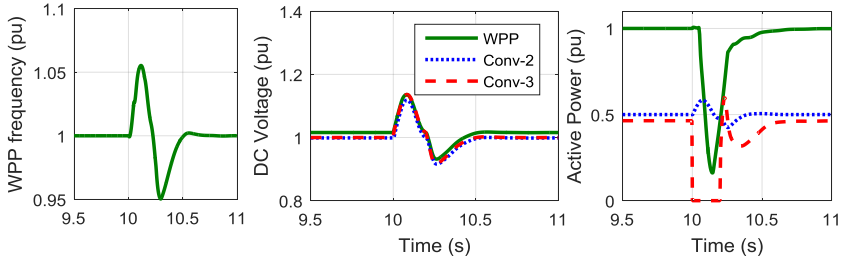

Fig. 7. WPP frequency, DC Voltage, Active Power of DC Grid with coordinated control from WPP

\section{DC Grid Voltage Control Service}

The dynamic challenges imposed by DC grid voltage control are critical and therefore a very fast control action is required to ensure stable operation. The increased connection of OWPPs to the DC grid requires OWPPs to participate in DC grid voltage control. To study the proposed coordinated control action, a disturbance is created in the DC Grid voltage by applying a step changes in power reference of Conv-2 at $\mathrm{t}=10 \mathrm{~s}$ (from $0.5 \mathrm{pu}$ to $0.55 \mathrm{pu}$ ) and $\mathrm{t}=15 \mathrm{~s}(0.55 \mathrm{pu}$ to $0.45 \mathrm{pu}$ ). 
With the coordinated control, the frequency of the offshore AC grid is modulated, as shown in Fig. 8, according DC grid voltage variations, as shown in Fig. 9. The frequency triggers the active power control from WPP leading to reduced DC voltage variations. Without coordinated control, Conv-3 alone modulates its power output to control the DC voltage. However, with the coordinated control, participation of WPP reduces the burden on the Conv-3 and the DC voltage profile is also improved.

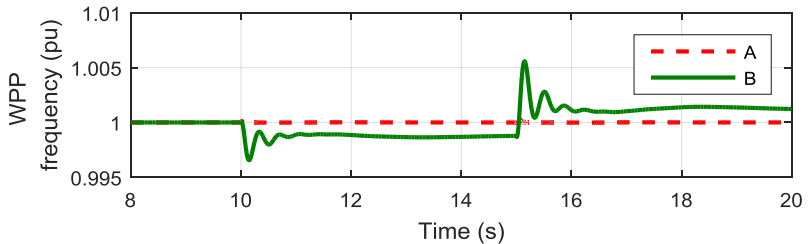

Fig. 8. Offshore AC grid frequency for active power disturbance at Conv- 2 Without (A) and With (B) coordinated control from WPP

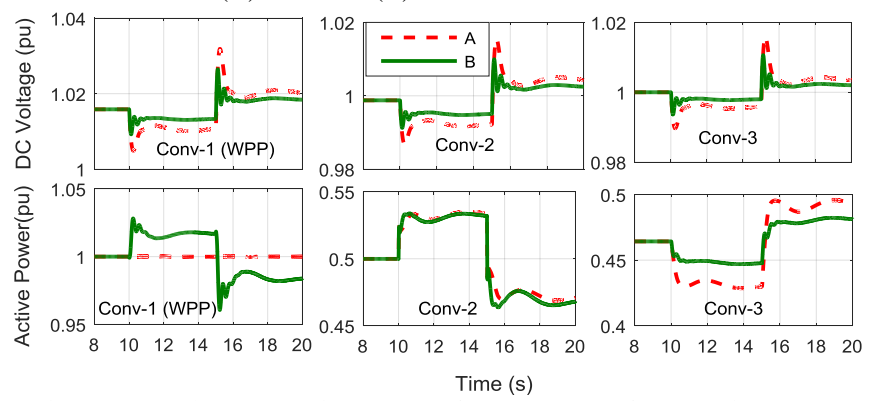

Fig. 9. DC Voltage \& Active Power of 3 Converters for an active power disturbance at Conv-2 (for A and B refer Fig 8)

\section{Possible limitations of the coordinated control method}

As described previously, the proposed coordinated control method has good performance. However, it also presents some possible practical limitations, i.e. the accuracy and speed of the frequency measurement may influence the performance of the proposed method. Another limitation is the active power rate limiter of the WPPs which may influence the power output and hence the frequency control performance. For onshore FRT support, the OWPP output should be reduced within few $100 \mathrm{~ms}$ and this is only possible by draining the energy from the OWPPs by DC chopper inside the WT converter. The installation of DC chopper inside the WT is easy and less expensive option compared to the DC chopper at onshore HVDC terminals. For DC voltage control from WPPs, it is possible to reduce the WPP power output by increasing the rotor speed (i.e. storing kinetic energy) and then changing the pitch angle by the pitch control. However, to increase the active power output, it is not recommended to overload the WT for longer duration, therefore, it is recommended to down regulate the WPP to have some power reserves. The faults in the DC grid may also lead to low DC voltage. In that case, it may not advisable that WPP contribute more power to DC grid. Hence, the proposed coordinated control scheme should be coordinated with DC grid protection settings.

\section{CONCLUSIONS}

A coordinated control methodology for providing ancillary services for AC grid (frequency and FRT support ) and DC grids (DC voltage control), from offshore wind power plants connected through multi-terminal HVDC network is described and demonstrated. For the onshore frequency control, the proposed control strategy involves a coordinated control mechanism based on DC voltage regulation at the onshore converter and the frequency regulation at the offshore converter. For onshore $\mathrm{AC}$ fault ride through, and DC Grid voltage control, the control strategy involves regulating the offshore AC grid frequency according to DC voltage variation. Based on detailed simulations on the 3terminal HVDC system, it is shown that with the proposed coordinated control strategy, offshore wind power plants can effectively deliver the ancillary services to DC and AC grids without any conflict of interest between each service. Finally, the limitations of the proposed control strategy are addressed.

\section{REFERENCES}

[1] Windspeed 2015. [Online]. Available: http://www.windspeed.eu. [Accessed: 25- Sep- 2015].

[2] M. Aragues Penalba, O. Gomis-Bellmunt and M. Martins," Coordinated Control for an Offshore Wind Power Plant to Provide Fault Ride Through Capability", IEEE Trans. Sustainable Energy, vol. 5, pp. 1253-1261, Sep 2014.

[3] Oriol Gomis-Bellmunta, J. Liang, J. Ekanayake, R. King, N. Jenkins, "Topologies of multiterminal HVDC-VSC transmission for large offshore wind farms," Electric Power Systems Research, vol. 81, pp, 271-281, Feb 2011.

[4] ENTSO- E, Draft- The Network Code on High Voltage Direct Current Connections (NC HVDC), Apr 2014.

[5] Tennet TSO GmbH, Requirements for Offshore grid Connections in the grid of Tennet TSO GmbH, Germany, Dec. 2012, pp. 1-10.

[6] L. Zeni, B. Hesselnæk, P.E.Sørensen, A.D.Hansen, P.C.Kjær,"Power System Services from VSC-HVDC Connected WPPs: an Overview" in Proc. 2015 14th Wind Integration Workshop, pp. 1-5.

[7] Y. Phulpin, "Communication-free inertia and frequency control for wind generators connected by an HVDClink," IEEE Trans on Power Systems, vol. 27, pp. 1136-1137, May 2012

[8] L. Zeni, I. Margaris, A. Hansen, P. Sørensen and P. Kjær, "Generic Models of Wind Turbine Generators for Advanced Applications in a VSC-based Offshore HVDC Network, " in Proc. 2012 10th IET Conference on AC/DC Transmission, Birmingham.

[9] B. Silva,C. L. Moreira, et al,"Provision of Inertial and Primary Frequency Control Services Using Offshore Multiterminal HVDC Network," IEEE Trans. on Sust. Energy, vol. 3, pp. 800-808, Oct 2012.

[10] S. Nanou, S. Papathanassiou,"Evaluation of a communication-based fault ride-through scheme for offshore wind farms connected through high-voltage DC links based on voltage source converter," IET Rene. Power Generation, , pp. 1-10, Jan 2015.

[11] B. Silva,C. L. Moreira, et al,"Control strategies for AC Fault Ride Through in Multiterminal HVDC Grids" IEEE Trans. Power Delivery, vol. 29, Feb 2014

[12] L. Zeni, "Power System Integration of VSC-HVDC connected Offshore Wind Power Plants " Ph.D thesis, DTU, Denmark, 2015.

[13] P. Kundur, "Power system stability and control", $4^{\text {th }}$ edition, McGrawHill 1994, New York.

[14] T. K. Vrana, J. Beerten, R. Belmans and O. B. Fosso, "A classification of DC node voltage control methods for HVDC grids," Electric power systems research, vol. 103, pp. 137-144, 2013.

[15] DIgSILENT GmbH, Technical Reference - PWM Converter.,2015.

[16] E. Muljadi et al. "Method of equivalencing for a large wind power plant with multiple turbine representation,"in Proc. 2008 IEEE Power and Energy Society General Meeting, pp-1-8.

[17] Electrical simulation models for wind power generation Wind turbine, IEC 61400-27-1, 2015.

[18] A. D. Hansen, I. Margaris, G. C. Tarnowski and F. Iov,"Simplified type 4 wind turbine modeling for future ancillary services," in Proc. 2013 European Wind Energy Conference, pp. 768-774. 